\title{
Angiopoietin-like protein 2 and angiopoietin-like protein 6 levels in patients with nonalcoholic fatty liver disease
}

\author{
Gulbanu Erkan ${ }^{1}$, Suzan Muratoglu², Ugur Ercin ${ }^{3}$, Ayse Bilgihan ${ }^{2}$
}

1Department of Internal Medicine, Division of Gastroenterology, Istanbul Medipol
University, Istanbul, Turkey
${ }^{2}$ Department of Biochemistry, Faculty of Medicine, Gazi University, Ankara, Turkey
${ }^{3}$ Balıkesir Public Health Directorate of Medical Laboratory, Balıkesir, Turkey

Submitted: 11 March 2016

Accepted: 19 May 2016

Arch Med Sci 2018; 14, 4: 781-787

DOI: https://doi.org/10.5114/aoms.2016.61811

Copyright $\odot 2016$ Termedia \& Banach

\section{Abstract}

Introduction: The aim of the current study was to examine the difference between patients detected with nonalcoholic fatty liver disease (NAFLD) and healthy subjects in terms of serum angiopoietin-like protein (ANGPTL) 2 and ANGPTL6 levels and to evaluate the correlation between ANGPTL2 and ANGPTL6 levels and liver enzyme levels, fasting glucose, lipid levels, and steatosis degree on ultrasonography (USG).

Material and methods: A total of 159 participants were included in the study. The participants were divided into 3 groups depending on the steatosis degree on USG and serum alanine aminotransferase (ALT) levels: the NAFLD group with increased ALT, the NAFLD group with normal ALT, and the healthy control group. The groups were compared in terms of biochemical and ultrasonographic findings, insulin resistance, metabolic syndrome (MetS), and anthropometric parameters.

Results: There was no significant difference between NAFLD patients and healthy subjects with respect to serum ANGPTL2 and ANGPTL6 levels $(p>0.05)$ ANGPTL2 levels did not correlate with serum, biochemical, or ultrasonographic findings, or anthropometric parameters $(p>0.05)$. A positive correlation was found between serum ANGPTL6 levels and fasting blood glucose, ALT, alkaline phosphatase, $\gamma$-glutamyl transpeptidase, fasting insulin, and HOMA-IR levels. Conclusions: While our findings suggest no relationship between serum ANGPTL2 and ANGPTL6 levels and NAFLD, ANGPTL6 levels may be related to metabolic and biochemical parameters. The effects of ANGPTL2 and ANGPTL6 in the pathogenesis of NAFLD should be investigated further.

Key words: nonalcoholic fatty liver disease, angiopoietin-like protein 2, angiopoietin-like protein 6.

\section{Introduction}

Non-alcoholic fatty liver disease (NAFLD) is a common hepatic disorder characterized by the concentration of fat greater than $5 \%$ of liver weight in the presence of $<20 \mathrm{~g} /$ day of alcohol intake and no evidence of other causes of hepatic disease [1]. Non-alcoholic fatty liver disease has a strong relationship with insulin resistance (IR) and obesity and is currently considered to be the manifestation of the metabolic syndrome (MetS) in the liver [2].

Metabolic syndrome is defined as a combination of risk factors for cardiovascular disease (CVD) including abdominal fat, dyslipidemia, IR, hypertension $(\mathrm{HT})$, and glucose intolerance. Of these, obesity and IR are two

\author{
Corresponding author: \\ Dr. Gulbanu Erkan Assoc. \\ Prof. \\ Department of Internal \\ Medicine \\ Division of Gastroenterology \\ Istanbul Medipol University \\ Medipol Mega Üniversite \\ Hastanesi TEM Avrupa \\ Otoyolu Göztepe \\ Çıkısı No: 1 \\ 34214 Istanbul, Turkey \\ Phone: +90 2124607070 \\ E-mail: gcanbaloglu@yahoo. \\ com
}


major components of the MetS and have a close relationship with the progression of NAFLD [3].

Recently, a novel family of proteins has been identified and recognized as 'angiopoietin-like proteins' (ANGPTLs), which exhibit structural similarities with angiogenic-regulating factors that are known as angiopoietins [4]. In humans, the ANGPTL2 level is increased in obesity (especially due to visceral fat) and is closely related to the levels of systemic IR and inflammation [5]. ANGPTL6, also called angiopoietin-like growth factor (AGF), is considered to counteract obesity through the elevation of systemic energy expenditure and the prevention of subsequent metabolic disease [6].

Literature reviews indicate that there has been no study investigating serum ANGPTL2 and ANGPTL6 levels in NAFLD. Serum ANGPTL2 and ANGPTL6 levels have been reported to be elevated in diabetic and obese patients in numerous previous studies [5, 7, 8]; therefore, we included nonobese, non-diabetic NAFLD patients in our study.

The current study was aimed to investigate:

- the difference between NAFLD patients and healthy subjects with respect to serum ANGPTL2 and ANGPTL6 levels,

- the difference between NAFLD patients and healthy subjects with respect to MetS and insulin resistance, and,

- the association between ANGPTL2 and ANGPTL6 levels and fasting glucose, lipid levels, liver lipid levels, enzyme levels, and the degree of steatosis on ultrasonography.

\section{Material and methods}

The study was conducted on 159 participants, including 46 non-obese, non-diabetic patients who presented with dyspeptic complaints and hepatosteatosis on USG and had a minimum 6-month history of elevated liver enzyme levels (group I), 62 patients who presented with hepatosteatosis on USG and normal liver function tests (group II), and 51 healthy controls (control group). Approval was obtained from the Local Ethics Committee and informed consent was obtained from all the participants. The study was conducted in line with the principles of the Declaration of Helsinki.

The inclusion criteria employed in the study were as follows: a body mass index (BMI) of 18.5$25 \mathrm{~kg} / \mathrm{m}^{2}$, presence of hepatosteatosis on USG, and negative markers for metabolic, autoimmune, and viral liver diseases.

Exclusion criteria included: presence of diabetes mellitus (DM) or impaired glucose tolerance, positive markers for metabolic, autoimmune, and viral liver diseases such as hepatitis B virus (HBV), hepatitis $C$ virus (HCV), and autoimmune hepatitis, use of drugs that lead to hepatic steatosis such as corticosteroids, oral contraceptives, methotrex- ate, tetracycline, and amiodarone, excessive consumption of ethanol ( $>20 \mathrm{~g} /$ day), and presence of chronic liver disease, biliary tract dilatation, and hepatic nodule and mass on USG.

The control group included non-obese, non-diabetic participants with negative markers for viral, metabolic, and autoimmune liver diseases, a BMI of $18.5-25 \mathrm{~kg} / \mathrm{m}^{2}$, no history of diabetes, no antidiabetic drug use, normal postprandial and fasting blood glucose and glycated hemoglobin $\left(\mathrm{HbA}_{1 \mathrm{c}}\right)$ levels, and normal liver parenchyma and biliary system on USG.

All the participants were examined for the presence of diabetes, impaired glucose tolerance, hypertension, cardiovascular disease, and use of ethanol. Height, weight, and waist circumference were measured and converted to the nearest half-cm or half$\mathrm{kg}$ units. The measurement of the waist circumference was performed at the midpoint between the iliac crest and the lower border of the rib cage.

Presence of HT was defined as the use of antihypertensive drugs or having a resting recumbent blood pressure of $\geq 140 / 90 \mathrm{~mm} \mathrm{Hg}$ on a minimum of two measurements. Following the measurement of height and weight, the calculation of BMI was achieved by dividing the weight $(\mathrm{kg})$ by the squared height $\left(\mathrm{m}^{2}\right)$.

\section{Measurement of biochemical parameters}

Blood collection was intravenously performed in the morning after overnight fasting (12 h). Serum and EDTA plasma aliquots were centrifuged and then stored at $-70^{\circ} \mathrm{C}$ until analysis. Serum levels of alanine aminotransferase (ALT), aspartate aminotransferase (AST), $\gamma$-glutamyl transpeptidase (GGT), triglycerides (TG), alkaline phosphatase (ALP), fasting blood glucose (FBG), high-density lipoprotein (HDL) cholesterol, total bilirubin and albumin, and total cholesterol (T. Cho) were measured using the standard techniques of clinical chemistry laboratories and used for clinical analysis. Calculation of low-density lipoprotein (LDL) cholesterol was achieved by using Friedewald's equation.

Serum glucose levels were measured using the Hexokinase/G-6-PDH technique (Abbott Architect C8000 System Analyzer, Abbott Laboratories, Abbott Park, Illinois, USA), and the measurement of insulin levels was achieved by using the chemiluminescent microparticle immunoassay (CMIA) technique (Abbott Architect i2000sr System Analyzer, Abbott Laboratories, Abbott Park, Illinois, USA).

Quantification of serum ANGPTL2 concentrations was performed using a commercially available enzyme-linked immunosorbent assay (ELISA) kit (USCNLIFE, catalog no: E91919HU, Export Processing Zone Building F, Wuhan, Hubei 430056, $P R C$ ) in accordance with the guidelines of the manufacturer. Quantification of serum ANGPTL6 
concentrations was performed using a commercially available ELISA kit (USCNLIFE, catalog no: E82468HU, Export Processing Zone Building F, Wuhan, Hubei 430056, PRC) in accordance with the guidelines of the manufacturer.

\section{Definition of metabolic syndrome}

Presence of MetS was defined as the detection of 3 or more of the components reported by the revised Adult Treatment Panel (ATP) III of the National Cholesterol Education Program [9]. These components have been reported as follows: 1) increased waist circumference (waist circumference of $102 \mathrm{~cm}$ or greater in males or $88 \mathrm{~cm}$ or greater in females); 2) elevated triglyceride ( $\geq 150 \mathrm{mg} / \mathrm{dl}$ ); 3) decreased HDL cholesterol ( $<40 \mathrm{mg} / \mathrm{dl}$ for males and $<50 \mathrm{mg} / \mathrm{dl}$ for females); 4) increased blood pressure ( $\geq 130 / 85 \mathrm{~mm} \mathrm{Hg}$ or taking hypertensive drugs); 5) elevated fasting glucose ( $\geq 100 \mathrm{mg} / \mathrm{dl}$ or taking antihyperglycemic drugs).

\section{Definition of IR}

Presence of IR was defined in accordance with the homeostasis model assessment index (HOMA$I R)$, and the calculation of IR was performed using the computer-based solution of the model developed by the Diabetes Trials Unit, Oxford Center for Diabetes, Endocrinology, and Metabolism. The cut-off value accepted for HOMA-IR was 2.7 [10]. Patients were divided into two groups, insulin-sensitive (HOMA-IR < 2.7) and insulin-resistant (HOMA$I R \geq 2.7)$, depending on their HOMA-IR levels.

\section{Hepatic ultrasonography}

Hepatic ultrasonography was performed by an experienced gastroenterologist. Diagnosis of fatty liver was established using the standard criteria reported in the literature, which include deep beam attenuation, bright vessel walls, liver to kidney contrast, and parenchymal brightness [11].

\section{Statistical analysis}

All data were analyzed using SPSS 15.0 for Windows (Chicago, IL, USA). Continuous variables were presented as mean \pm standard deviation (SD), or median and minimum-maximum values where appropriate. Categorical variables were expressed as counts and percentages. Normality of distribution was assessed using the Shapiro-Wilk test, and the homogeneity of variance was tested using the Levene test. The difference in numerical variables among multiple groups was tested using one-way ANOVA or Welch variance for parametric data and the Kruskal Wallis test for non-parametric data. Following these tests, the Tukey HSD, Games-Howell test, and the Dunn test were used for pairwise comparisons, respectively. The difference in terms of numerical variables between two groups was assessed using the $t$-test for parametric data and the Mann-Whitney $U$ test for non-parametric data. The $\chi^{2}$ test was used to assess the differences between the groups in terms of categorical variables. The correlation between numerical variables was evaluated using the Spearman correlation coefficient. A $p$-value of $<0.05$ was accepted as statistically significant.

\section{Results}

\section{Demographic, metabolic and biochemical findings}

The study included a total of 159 participants: 46 non-obese, non-diabetic patients who presented with dyspeptic complaints and hepatosteatosis on USG and had a minimum 6-month history of elevated liver enzyme levels (group I); 62 patients who presented with hepatosteatosis on USG and had normal liver function tests (group II); and 51 healthy controls (control group). Table I summarizes the demographic and biochemical findings of the groups.

Significant differences were observed among the 3 groups with respect to HT $(37 \%, 58.1 \%$, $7.8 \%$, respectively; $p<0.001)$, MetS $(34.8 \%, 29 \%$, $5.9 \%$, respectively; $p=0.001)$, IR $(58.7 \%, 41.9 \%$, $11.8 \%$, respectively; $p<0.001)$, age $(44.9 \pm 12.7$, $55.4 \pm 15.1,35 \pm 12.3$, respectively; $p<0.001)$, BMI $\left(24.2 \pm 0.6 \mathrm{~kg} / \mathrm{m}^{2}, 23.4 \pm 1.5 \mathrm{~kg} / \mathrm{m}^{2}, 22.4 \pm 1.7 \mathrm{~kg} /\right.$ $\mathrm{m}^{2}$, respectively; $p<0.001$ ), AST (34 IU/l, $19 \mathrm{IU} / \mathrm{l}$, $16 \mathrm{lU} / \mathrm{l} ; p<0.001)$, ALT (62 IU/l, $21 \mathrm{lU} / \mathrm{l}, 16 \mathrm{lU} / \mathrm{l}$, respectively; $p=0.001)$, and GGT $(60.3 \pm 32.9 \mathrm{IU} / \mathrm{l}$, $25.7 \pm 12.2 \mathrm{IU} / \mathrm{l}, 20 \pm 10.5 \mathrm{IU} / \mathrm{l}$, respectively; $p<0.001)$. Groups I and II had significantly higher levels in waist circumference (WC) $(85.7 \pm 7.7 \mathrm{~cm}$, $83.9 \pm 8.2 \mathrm{~cm}$ vs. $79.3 \pm 8.1 \mathrm{~cm} ; p<0.01)$, waist/ hip ratio (WHR) (0.9 $\pm 0.1,0.9 \pm 0.1$ vs. $0.8 \pm 0.1$; $p<0.001)$, FBG $(95.3 \pm 8.6 \mathrm{mg} / \mathrm{dl}, 97.2 \pm 7.6 \mathrm{mg} /$ dl vs. $88.2 \pm 9.3 \mathrm{mg} / \mathrm{dl} ; p<0.001)$, fasting insulin (13.1 $\mu \mathrm{U} / \mathrm{ml}, 9.7 \mu \mathrm{U} / \mathrm{ml}$ vs. $6.9 \mu \mathrm{U} / \mathrm{ml} ; p<0.001)$, and HOMA-IR $(3.3,2.5$ vs. $1.5 ; p<0.001)$ compared to the control group, whereas these parameters showed no significant difference between groups I and II ( $p>0.05)$. Moreover, no significant difference was observed among the three groups in terms of serum ANGPTL2 $(6.8 \mathrm{ng} / \mathrm{ml}, 7.2 \mathrm{ng} /$ $\mathrm{ml}, 6.8 \mathrm{ng} / \mathrm{ml}$, respectively; $p=0.55)$ or ANGPTL6 levels $(967 \mathrm{pg} / \mathrm{ml}, 721 \mathrm{pg} / \mathrm{ml}, 756.2 \mathrm{pg} / \mathrm{ml}$, respectively; $p=0.73)(p>0.05)$.

\section{Relationship between serum ANGPTL2 levels and demographic, clinical and laboratory findings}

Serum ANGPTL2 level showed no significant difference between females and males $(10.2 \pm 7.5 \mathrm{ng} /$ $\mathrm{ml}$ vs. $8.3 \pm 5.9 \mathrm{ng} / \mathrm{ml} ; p=0.059)$, between $\mathrm{pa}$ - 
Table I. Demographic and biochemical findings of the groups

\begin{tabular}{|c|c|c|c|c|c|}
\hline \multicolumn{2}{|c|}{ Parameter } & \multirow{2}{*}{$\begin{array}{c}\text { Group I }(N=46) \\
n(\%)\end{array}$} & \multirow{2}{*}{$\begin{array}{c}\text { Group II }(N=62) \\
n(\%)\end{array}$} & \multirow{2}{*}{$\begin{array}{c}\text { Group III }(N=51) \\
n(\%)\end{array}$} & \multirow[t]{2}{*}{$P$-value } \\
\hline & & & & & \\
\hline \multirow[t]{2}{*}{ Gender } & Female & $12(26.1)$ & $31(50.0)$ & $27(52.9)$ & 0.014 \\
\hline & Male & $34(73.9)$ & $31(50.0)$ & $24(47.1)$ & \\
\hline \multicolumn{2}{|c|}{ Hypertension } & $17(37.0)$ & $36(58.1)$ & $4(7.8)$ & $<0.001$ \\
\hline \multicolumn{2}{|l|}{ MetS } & $16(34.8)$ & $18(29.0)$ & $3(5.9)$ & 0.001 \\
\hline \multirow{2}{*}{\multicolumn{2}{|c|}{ IR }} & $27(58.7)$ & $26(41.9)$ & $6(11.8)$ & $<0.001$ \\
\hline & & Mean \pm SD & Mean \pm SD & Mean \pm SD & \\
\hline \multicolumn{2}{|c|}{ Age [years] } & $44.9 \pm 12.7$ & $55.4 \pm 15.1$ & $35 \pm 12.8$ & $<0.001^{* \neq \neq}$ \\
\hline \multicolumn{2}{|c|}{ BMI $\left[\mathrm{kg} / \mathrm{m}^{2}\right]$} & $24.2 \pm 0.6$ & $23.4 \pm 1.5$ & $22.4 \pm 1.7$ & $<0.001^{*+\neq}$ \\
\hline \multicolumn{2}{|c|}{$W C[\mathrm{~cm}]$} & $85.7 \pm 7.7$ & $83.9 \pm 8.2$ & $79.3 \pm 8.1$ & $<0.001^{\star \dagger}$ \\
\hline \multicolumn{2}{|c|}{ FBG $[\mathrm{mg} / \mathrm{dl}]$} & $95.3 \pm 8.6$ & $97.2 \pm 7.6$ & $88.2 \pm 9.3$ & $<0.001^{\star \dagger}$ \\
\hline \multicolumn{2}{|c|}{ GGT [IU/I] } & $60.3 \pm 32.9$ & $25.7 \pm 12.2$ & $20 \pm 10.5$ & $<0.001^{* \neq}$ \\
\hline \multicolumn{2}{|c|}{ Triglyceride $[\mathrm{mg} / \mathrm{dl}]$} & $145.7 \pm 58.2$ & $122.2 \pm 54$ & $102.9 \pm 57.4$ & $0.001^{\dagger}$ \\
\hline \multicolumn{2}{|c|}{ Total cholesterol [mg/dl] } & $195.3 \pm 39.6$ & $181.4 \pm 35.8$ & $164.8 \pm 25.6$ & $<0.001^{*+}$ \\
\hline \multirow{2}{*}{\multicolumn{2}{|c|}{ LDL cholesterol [mg/dl] }} & $117.1 \pm 31.8$ & $104.4 \pm 35.9$ & $95.5 \pm 22$ & $0.001^{\dagger}$ \\
\hline & & Median (min.-max.) & Median (min.-max.) & Median (min.-max.) & \\
\hline \multicolumn{2}{|c|}{ AST [IU/I] } & $34(21-89)$ & $19(10-34)$ & $16(11-25)$ & $<0.001^{*+\ddagger}$ \\
\hline \multicolumn{2}{|c|}{ ALT [IU/I] } & $62(47-152)$ & $21(8-39)$ & $16(9-38)$ & $<0.001^{*+\neq}$ \\
\hline \multicolumn{2}{|c|}{ HDL cholesterol [mg/dl] } & $41.5(23-72)$ & $46(26-80)$ & $52(22-88)$ & 0.092 \\
\hline \multicolumn{2}{|c|}{ Total bilirubin [mg/dl] } & $0.5(0.24-1.2)$ & $0.6(0.16-2)$ & $0.5(0.24-1.16)$ & 0.759 \\
\hline \multicolumn{2}{|c|}{ Direct bilirubin [mg/dl] } & $0.2(0.04-0.7)$ & $0.2(0.09-0.6)$ & $0.2(0.03-0.42)$ & 0.204 \\
\hline \multicolumn{2}{|c|}{ Fasting insulin $[\mu \mathrm{U} / \mathrm{ml}]$} & $13.1(2.1-125.1)$ & $9.7(2.8-63.4)$ & $6.9(2.6-23.2)$ & $<0.001^{* \dagger}$ \\
\hline \multicolumn{2}{|c|}{ HOMA-IR } & $3.3(0.5-25)$ & $2.5(0.6-15.3)$ & $1.5(0.4-5)$ & $<0.001^{\star \dagger}$ \\
\hline \multicolumn{2}{|c|}{ ANGPTL2 [ng/ml] } & $6.8(3.1-25.1)$ & $7.2(1.3-30)$ & $6.8(1.7-30)$ & 0.559 \\
\hline \multicolumn{2}{|c|}{ ANGPTL6 [pg/ml] } & $967.6(267.6-2612.8)$ & $721.1(27.9-3237.1)$ & $756.2(25.2-4319.7)$ & 0.730 \\
\hline
\end{tabular}

WC - waist circumference, Met $S$ - metabolic syndrome, FBG - fasting blood glucose, HDL - high-density lipoprotein, TG - triglycerides, $I R$ - insulin resistance, $B M I$ - body mass index, HOMA-IR - index of insulin resistance calculated according to the HOMA (homeostasis model assessment) method, T. cholesterol - total cholesterol, LDL - low-density lipoprotein, AST - aspartate aminotransferase, $A L T$ - alanine aminotransferase (ALT), GGT - $\gamma$-glutamyl transpeptidase. * Group II different from group III, ${ }^{\dagger}$ group I different from group III, ${ }^{\ddagger}$ group I different from group II.

tients with and without $\mathrm{HT}(8.3 \pm 6.8 \mathrm{ng} / \mathrm{ml}$ vs. 9.6 $\pm 6.6 \mathrm{ng} / \mathrm{ml} ; p=0.058$ ), between patients with and without MetS $(9.8 \pm 7.1 \mathrm{ng} / \mathrm{ml}$ vs. $9 \pm 6.6 \mathrm{ng} / \mathrm{ml}$; $p=0.44)$, or between patients with and without IR $(9.3 \pm 7.1 \mathrm{ng} / \mathrm{ml}$ vs. $9.1 \pm 6.5 \mathrm{ng} / \mathrm{ml} ; p=0.99)$. No significant correlation was found between serum ANGPTL level and the steatosis level detected on USG $(p>0.05)$. Moreover, serum ANGPTL2 exhibited no significant correlation with age $(r=-0.04$; $p=0.56)$, BMI $(r=-0.04 ; p=0.58)$, WC $(r=-0.12$; $p=0.10)$, WHR $(r=-0.01 ; p=0.90)$, FBG $(r=0.03$; $p=0.68)$, AST $(r=-0.05 ; p=0.47)$, ALT $(r=-0.003$; $p=0.97), \operatorname{ALP}(r=0.017 ; p=0.83), \mathrm{GGT}(r=-0.09$; $p=0.25)$, ALB $(r=-0.004 ; p=0.96)$, total cholesterol $(r=0.05 ; p=0.48)$, LDL cholesterol $(r=0.058$; $p=0.47)$, HDL cholesterol $(r=-0.056 ; p=0.53)$, TG $(r=0.10 ; p=0.18)$, total bilirubin $(r=-0.01$; $p=0.89)$, direct bilirubin $(r=-0.05 ; p=0.46)$, fasting insulin $(r=0.04 ; p=0.54)$, HOMA-IR $(r=0.04$; $p=0.59)$, or ANGPTL6 level $(r=-0.06 ; p=0.44)$.

\section{Relationship between ANGPTL6 levels} and demographic, clinical and laboratory findings

Table II presents the relationship between ANGPTL6 level and demographic and clinical 
Table II. Relationship between serum ANGPTL6 level and demographic and clinical findings

\begin{tabular}{|c|c|c|c|c|}
\hline Parameter & & Mean \pm SD & Median (min.-max.) & $P$-value \\
\hline \multirow[t]{2}{*}{ Gender } & Female $(n=70)$ & $963.0 \pm 763.3$ & $782.7(25.2-4319.7)$ & \multirow[t]{2}{*}{0.737} \\
\hline & Male $(n=88)$ & $983.6 \pm 704.9$ & $756.2(78.3-3237.1)$ & \\
\hline \multirow[t]{2}{*}{ Hypertension } & Absent $(n=102)$ & $944.4 \pm 801.3$ & $659.9(25.2-4319.7)$ & \multirow[t]{2}{*}{0.053} \\
\hline & Present $(n=56)$ & $1029.8 \pm 575.8$ & $895.5(185.8-2896.6)$ & \\
\hline \multirow[t]{2}{*}{ MetS } & Absent $(n=121)$ & $953.6 \pm 767.4$ & $756.2(25.2-4319.7)$ & \multirow[t]{2}{*}{0.136} \\
\hline & Present $(n=37)$ & $1041.8 \pm 592.8$ & $952.5(286.9-2896.6)$ & \\
\hline \multirow[t]{2}{*}{ IR } & Absent $(n=100)$ & $862.0 \pm 661.3$ & $659.9(25.2-3147.0)$ & \multirow[t]{2}{*}{0.004} \\
\hline & Present $(n=58)$ & $1169.8 \pm 802.7$ & $1064.7(78.3-4319.7)$ & \\
\hline \multirow{4}{*}{$\begin{array}{l}\text { Ultrasonographic } \\
\text { steatosis grade }\end{array}$} & Absent $(n=50)$ & $988.5 \pm 893.7$ & $756.2(25.2-4319.7)$ & \multirow[t]{4}{*}{0.803} \\
\hline & Mild $(n=33)$ & $951.3 \pm 703.8$ & $756.3(27.9-3237.1)$ & \\
\hline & Moderate $(n=42)$ & $933.5 \pm 607.7$ & $772.6(54.4-2612.8)$ & \\
\hline & Severe $(n=33)$ & $1029.6 \pm 636.1$ & $869.1(286.9-2896.6)$ & \\
\hline \multicolumn{2}{|l|}{ Parameter } & \multicolumn{2}{|c|}{ Correlation coefficient } & $P$-value \\
\hline \multicolumn{2}{|l|}{ Age [years] } & \multicolumn{2}{|c|}{0.115} & 0.154 \\
\hline \multicolumn{2}{|l|}{ BMI $\left[\mathrm{kg} / \mathrm{m}^{2}\right]$} & \multicolumn{2}{|c|}{-0.073} & 0.364 \\
\hline \multicolumn{2}{|l|}{$W C[\mathrm{~cm}]$} & \multicolumn{2}{|c|}{0.003} & 0.971 \\
\hline
\end{tabular}

Met $S$ - metabolic syndrome, IR - insulin resistance, $B M I-$ body mass index, WC - waist circumference.

findings. Serum ANGPTL6 level showed no significant difference between females and males (963 $\pm 763.3 \mathrm{pg} / \mathrm{ml}$ vs. $983.6 \pm 704.9 \mathrm{pg} / \mathrm{ml} ; p=0.73)$, between patients with and without HT (1029.8 $\pm 575.8 \mathrm{pg} / \mathrm{ml}$ vs. $944.4 \pm 801.3 \mathrm{pg} / \mathrm{ml} ; p=0.053)$, or between patients with and without MetS (1041.8 $\pm 592.8 \mathrm{pg} / \mathrm{ml}$ vs. $953.6 \pm 767.4 \mathrm{pg} / \mathrm{ml} ; p=0.136)$ $(p>0.05)$. Moreover, the serum ANGPTL6 levels in the patients with IR were significantly higher compared to the patients without IR $(1169.8 \pm 802.7$ $\mathrm{pg} / \mathrm{ml}$ vs. $862 \pm 661.3 \mathrm{pg} / \mathrm{ml} ; p=0.004)$.

Serum ANGPTL6 level showed no significant correlation with age, BMI, WC, WHR, AST, ALB, LDL cholesterol, total cholesterol, HDL cholesterol, TG, direct bilirubin levels, or total bilirubin ( $p>0.05$ ). Nevertheless, serum ANGPTL6 level exhibited a significant positive correlation with FBG $(r=0.18 ; p=0.01)$, serum ALT $(r=0.19$; $p=0.017)$, ALP $(r=0.21 ; p=0.008), \mathrm{GGT}(r=0.19$; $p=0.01)$, fasting insulin $(r=0.272 ; p=0.001)$, and HOMA-IR $(r=0.27 ; p<0.001)$ (Table III).

\section{Discussion}

Non-alcoholic fatty liver disease affects almost $1 / 3$ of the general population around the world and may present an increase in cardiometabolic risk and resultant adverse cardiovascular events regardless of conventional cardiovascular risk factors and the MetS. Non-alcoholic fatty liver disease is mostly indicated by IR and is closely associated with obesity and type 2 diabetes. Non-alcoholic fatty liver disease is an indicator of pathological ectopic fat concentration with low-grade chronic

Table III. Correlations between serum ANGPTL6 level and laboratory findings

\begin{tabular}{|lcc|}
\hline Parameter & $\begin{array}{c}\text { Correlation } \\
\text { coefficient }\end{array}$ & $P$-value \\
\hline FBG [mg/dl] & 0.189 & 0.018 \\
\hline AST [IU/l] & 0.135 & 0.093 \\
\hline ALT [IU/l] & 0.192 & 0.017 \\
\hline ALP [IU/l] & 0.212 & 0.008 \\
\hline GGT [IU/l] & 0.194 & 0.015 \\
\hline Albumin $[\mathrm{mg} / \mathrm{dl}]$ & 0.044 & 0.584 \\
\hline T. cholesterol [mg/dl] & -0.066 & 0.414 \\
\hline LDL cholesterol [mg/dl] & 0.047 & 0.559 \\
\hline HDL cholesterol $[\mathrm{mg} / \mathrm{dl}]$ & -0.069 & 0.390 \\
\hline TG $[\mathrm{mg} / \mathrm{dl}]$ & 0.064 & 0.431 \\
\hline Fasting insulin $[\mu \mathrm{U} / \mathrm{ml}]$ & 0.272 & 0.001 \\
\hline HOMA-IR & 0.277 & $<0.001$ \\
\hline
\end{tabular}

FBG - fasting blood glucose, AST - aspartate aminotransferase, ALT - alanine aminotransferase ALP - alkaline phosphatase, GGT - $\gamma$-glutamyl transpeptidase, T. cholesterol - total cholesterol, $L D L$ - low-density lipoprotein, HDL - high-density lipoprotein, TG - triglycerides, HOMA-IR - index of insulin resistance calculated according to the HOMA (homeostasis model assessment) method. 
inflammation which leads to a number of adverse pathophysiological processes such as hypercoagulability, increased oxidative stress, endothelial dysfunction, fatty acid and lipoprotein metabolism, abnormal glucose, accelerated progression of atherosclerosis, and deranged adipokine profile [12].

Non-alcoholic fatty liver disease is mostly triggered by one or more features of the MetS, such as central obesity, hypertension, glucose intolerance or diabetes, IR, and dyslipidemia [2, 13-15]. There are a few studies reporting on the metabolic importance of NAFLD in non-obese, non-diabetic individuals. These studies have revealed that NAFLD has a closer relationship with IR and the markers of endothelial dysfunction and oxidative stress compared to the ATP III criteria in non-diabetic, non-obese individuals [16-18]. The literature shows that serum ANGPTL2 and ANGPTL6 levels are increased in obese and diabetic patients $[5,7,8]$. Therefore, we included non-obese non-diabetic NAFLD patients in our study, and we found a significant difference in IR, HT, and MetS presence among the three groups; these findings were consistent with the findings reported in the literature $[18,19]$.

ANGPTL2 is a protein that is secreted and regulates angiogenesis similarly to several other ANGPTLS [4]. ANGPTL2 is expressed in adipose tissue in large amounts [5]. In obese mice, both ANGPTL2 mRNA levels in adipose tissue and the protein levels in the circulation are increased. In humans, the circulating levels of ANGPTL2 are also increased in obesity (especially due to visceral obesity) and are closely associated with the levels of systemic IR and inflammation, and the circulating levels of ANGPTL2 are reported to decrease in parallel with body weight loss [5]. Conversely, the ANGPTL2 expressed in adipose tissue exhibits vascular inflammation in transgenic mice and leads to elevated macrophage infiltration in adipose tissue and increased expression of inflammatory cytokines, despite them being non-obese [5].

In our study, we investigated the ANGPTL2 level in NAFLD since ANGPTL2 is accompanied by systemic IR and increased inflammation in adipose tissue and circulation, and these findings have been demonstrated to have a key role in the pathogenesis of NAFLD and MetS [2, 12]. We excluded obese patients with DM since ANGPTL2 and ANGPTL6 have been shown to be increased in diabetes and obesity $[5,7,8]$. Nevertheless, no significant difference was found among the three groups with respect to ANGPTL2 levels. Moreover, there was no significant correlation among the demographic, biochemical or ultrasonographic findings and ANGPTL2 levels among the three groups. These results may be attributed to the limited number of patients in our study or may suggest that there may be mediators other than ANGPTL2 that may have a role in IR development in nondiabetic, non-obese NAFLD patients. We consider that further studies with large-scale designs are needed to validate these findings.

ANGPTL6, also known as AGF, is a protein belonging to the ANGPTL family that is mainly secreted from the hepatic tissue into the systemic circulation [6]. Oike et al. demonstrated that ANGPTL6-deficient mice presented remarkable fat concentration in the skeletal muscle and liver and IR with decreased energy consumption compared to controls. Similarly, several other studies have shown that mice with targeted activation of ANGPTL6 exhibit elevated insulin sensitivity and leanness caused by elevated energy consumption. These mice are also protected from high-fat diet-induced obesity as well as non-adipose tissue steatosis and IR [6].

A recent report revealed that human ANGPTL6 concentration in the circulation is increased in obesity or diabetes and ANGPTL6 concentration has a positive correlation with the fasting serum glucose levels [8]. Similarly, Kadomatsu et al. suggested that ANGPTL6 resistance is likely to occur in obesity or diabetes [4]. In our study, we excluded diabetic and obese patients since ANGPTL6 concentration is increased in these patients. Moreover, we found that serum ANGPTL6 levels in patients with IR were significantly higher than those without IR.

In this study, no significant difference was found among the three groups with regard to ANGPTL6 levels. Nevertheless, serum ANGPTL6 level displayed a positive correlation with FBG, serum ALT, ALP, GGT, fasting insulin, and HOMA-IR levels. The finding indicating the presence of a close association between serum ANGPTL6 level and FBG was consistent with the association found by Ebert et al. [8]. Ebert et al. revealed that the AGF level in the circulation is elevated in patients with DM type 2 and is associated with the method used in antidiabetic treatment but is not independently associated with insulin sensitivity and secretion indices, anthropometric measurements, or several other adipokines [20]. Similarly to the study conducted by Ebert et al., we also found no significant correlation between serum ANGPTL6 level and anthropometric measurements.

This study is limited in several ways. First, we used USG instead of biopsy in the diagnosis of NAFLD. USG remains the method of choice in the diagnosis of asymptomatic patients with elevated liver enzyme levels and suspected NAFLD. Nevertheless, USG fails to provide quantitative data regarding fat accumulation, liver inflammation, or fibrosis [21]. Another limitation is that the control group was significantly younger than the patient group. Nevertheless, this was somewhat inevitable because we applied strict exclusion criteria, and 
it was not possible for us to recruit control subjects without diabetes, obesity, insulin resistance or hepatosteatosis who would exactly match the patient group in terms of age. Finally, our study had a relatively small sample size.

In conclusion, MetS, IR, and HT were significantly higher in non-obese, non-diabetic NAFLD patients in comparison to healthy controls. ANGPTL2 level showed no significant correlation with MetS, IR, $H T$, or ultrasonographic and biochemical findings. Serum ANGPTL6 level was found to be significantly higher in patients with IR than in patients without IR and showed a positive correlation with FBG, ALT, ALP, GGT, fasting insulin, and HOMA-IR levels. Due to our relatively small sample size, these results need to be validated in larger study populations and in different ethnic groups. Further studies with large-scale designs are needed to elucidate the effects of ANGPTL2 and ANGPTL6 in the pathogenesis of NAFLD.

\section{Acknowledgments}

This study was financially aided by Gazi University Research Foundation (Project Number: 01/2012-14).

\section{Conflict of interest}

The authors declare no conflict of interest.

\section{References}

1. Angulo P. GI epidemiology: nonalcoholic fatty liver disease. Aliment Pharmacol Ther 2007; 25: 883-9.

2. Dowman JK, Tomlinson JW, Newsome PN. Systematic review: the diagnosis and staging of non-alcoholic fatty liver disease and non-alcoholic steatohepatitis. Aliment Pharmacol Ther 2011; 33: 525-40.

3. Kotronen A, Yki-Jarvinen H. Fatty liver. A novel component of the metabolic syndrome. Arterioscler Thromb Vasc Biol 2008; 28: 27-38.

4. Kadomatsu T, Tabata M, Oike Y. Angiopoietin-like proteins: emerging targets for treatment of obesity and related metabolic diseases. FEBS J 2011; 278: 559-64.

5. Tabata M, Kadomatsu T, Fukuhara S, et al. Angiopoietin-like protein 2 promotes chronic adipose tissue inflammation and obesity-related systemic insulin resistance. Cell Metab 2009; 10: 178-88.

6. Oike Y, Akao M, Yasunaga K, et al. Angiopoietin-related growth factor antagonizes obesity and insulin resistance. Nat Med 2005; 11: 400-8.

7. Li Q, Gong W, Yang Z, et al. Serum Angpt12 levels are independently associated with albuminuria in type $2 \mathrm{di}$ abetes. Diabetes Res Clin Pract 2013; 100: 385-90.

8. Ebert T, Bachmann A, Lössner U, et al. Serum levels of angiopoietin-related growth factor in diabetes mellitus and chronic hemodialysis. Metabolism 2009; 58: 547-51.

9. Grundy SM, Cleeman JI, Daniels SR, et al.; American Heart Association; National Heart, Lung, and Blood Institute. Diagnosis and management of the metabolic syndrome: an American Heart Association/National Heart, Lung, and Blood Institute Scientific Statement. Circulation 2005; 112: 2735-52.
10. Gokcel A, Ozsahin AK, Sezgin N, et al. High prevalence of diabetes in Adana, a southern province of Turkey. Diabetes Care 2003; 26: 3031-4.

11. Saverymuttu SH, Joseph AE, Maxwell JD. Ultrasound scanning in the detection of hepatic fibrosis and steatosis. Br Med J (Clin Res Ed) 1986; 292: 13-5.

12. Bhatia LS, Curzen NP, Calder PC, et al. Non-alcoholic fatty liver disease: a new and important cardiovascular risk factor? Eur Heart J 2012; 33: 1190-200.

13. Olufadi R, Byrne CD. Clinical and laboratory diagnosis of the metabolic syndrome. J Clin Pathol 2008; 61: 697-706.

14. Reynolds K, He J. Epidemiology of the metabolic syndrome. Am J Med Sci 2005; 330: 273-9.

15. Papaetis GS, Papakyriaoku P, Panagiotou TN. Central obesity, type 2 diabetes and insulin: exploring a pathway full of thrones. Arch Med Sci 2015; 11: 463-82.

16. Musso G, Gambino R, Bo S, et al. Should nonalcoholic fatty liver disease be included in the definition of metabolic syndrome? A cross-sectional comparison with Adult Treatment Panel III criteria in nonobese nondiabetic subjects. Diabetes Care 2008; 31: 562-8.

17. Sinn DH, Gwak GY, Park HN, et al. Ultrasonographically detected non-alcoholic fatty liver disease is an independent predictor for identifying patients with insulin resistance in non-obese, non-diabetic middle-aged Asian adults. Am J Gastroenterol 2012; 107: 561-7.

18. Kim HJ, Kim HJ, Lee KE, et al. Metabolic significance of nonalcoholic fatty liver disease in nonobese, nondiabetic adults. Arch Intern Med 2004; 164: 2169-75.

19. Erkan G, Sayin I, Polat FB, et al. The relationship between insulin resistance, metabolic syndrome and non-alcoholic fatty liver disease in non-obese non-diabetic Turkish individuals: a pilot study. Turk J Gastroenterol 2014; 25 (Suppl. 1): 63-8.

20. Ebert T, Kralisch S, Loessner U, et al. Relationship between serum levels of angiopoietin-related growth factor and metabolic risk factors. Horm Metab Res 2014; 46: 685-90.

21. Wieckowska A, Feldstein AE. Diagnosis of nonalcoholic fatty liver disease: invasive versus noninvasive. Semin Liver Dis 2008; 28: 386-95. 